This item was submitted to Loughborough's Research Repository by the author.

Items in Figshare are protected by copyright, with all rights reserved, unless otherwise indicated.

\title{
Development and testing of a micro wind tunnel for on-site wind erosion
}

\section{simulations}

\section{PLEASE CITE THE PUBLISHED VERSION}

http://dx.doi.org/10.1007/s10652-016-9478-8

\section{PUBLISHER}

(C) Springer Science+Business Media Dordrecht

\section{VERSION}

AM (Accepted Manuscript)

\section{PUBLISHER STATEMENT}

This work is made available according to the conditions of the Creative Commons Attribution-NonCommercialNoDerivatives 4.0 International (CC BY-NC-ND 4.0) licence. Full details of this licence are available at: https://creativecommons.org/licenses/by-nc-nd/4.0/

\section{LICENCE}

CC BY-NC-ND 4.0

\section{REPOSITORY RECORD}

Strong, Craig L., John Leys, Mike R. Raupach, Joanna Bullard, Helene A. Aubault, Harry J. Butler, and Grant H. McTainsh. 2019. "Development and Testing of a Micro Wind Tunnel for On-site Wind Erosion Simulations". figshare. https://hdl.handle.net/2134/22348. 
1 Development and testing of a micro wind tunnel for on-site wind erosion

2 simulations.

4 Craig L. Strong ${ }^{1 *}$, John F. Leys ${ }^{2}$, Mike R. Raupach ${ }^{3}$, Joanna E. Bullard ${ }^{4}$, Hélène A. Aubault ${ }^{4}$, 5 Harry J. Butler ${ }^{5}$ and Grant H. McTainsh ${ }^{6}$

$6 \quad 1^{*}$ Fenner School of Environment \& Society, The Australian National University, Canberra ACT 2601 Australia

$7 \quad{ }^{2}$ New South Wales Office of Environment and Heritage, Gunnedah, NSW 2380 Australia

$8{ }^{3}$ The Climate Change Institute, The Australian National University, Canberra ACT 2601 Australia (deceased)

$9 \quad{ }^{4}$ Department of Geography, Loughborough University, Leicestershire LE11 3TU United Kingdom

$10{ }^{5}$ School of Agricultural, Computational \& Environmental Sciences, University of Southern Queensland,

11 Toowwomba, QLD 4350 Australia

${ }^{6}$ Griffith School of Environment, Griffith University, Nathan Qld 4111 Australia

14 * craig.strong@anu.edu.au; Phone +61 26125 6683; Fax +61 261250746

\section{Abstract}

Wind erosion processes affect soil surfaces across all land uses worldwide. Understanding the spatial and temporal scales of wind erosion is a challenging undertaking because these processes are diverse and highly variable. Wind tunnels provide a useful tool as they can be used to simulate erosion at small spatial scales. Portable wind tunnels are particularly valued because erosion can be simulated on undisturbed soil surfaces in the field. There has been a long history of use of large portable wind tunnels, with consensus that these wind erosion simulation tools can meet real world aerodynamic criteria. However, one consequence of striving to meet aerodynamic reality is that the size of the tunnels has increased, making them logistically difficult to work with in the field and resulting in a tendency to homogenise naturally complex soil surfaces. This homogenisation is at odds with an increasing awareness of the importance that small scale processes have in wind erosion. To address these logistical and surface homogenisation issues we present here the development and testing of a micro wind tunnel (MWT) designed to simulate wind erosion processes at high spatial resolution. The MWT is a duct-type design $-0.05 \mathrm{~m}$ tall $0.1 \mathrm{~m}$ wide and with a $1.0 \mathrm{~m}$ working section. The tunnel uses a centrifugal motor to suck air through a flow-conditioning section, over the working section and then through a sediment collection trap. Simulated wind velocities range from 5 to $18 \mathrm{~m} \mathrm{~s}^{-1}$, with high reproducibility. Wind speeds are laterally uniform and values of $u_{*}$ at the tunnel bed (calculated by measuring the pressure gradients within the MWT) are comparable with those of larger tunnels in which logarithmic profiles can be developed. Saltation sediment can be added. The tunnel can be deployed by a single person and operated on slopes ranging from 0-10 degrees. Evidence is presented here that the MWT provides new and useful understanding of the erodibility of rangelands, claypans and ore stockpiles. 
41 Keywords. Erodibility, Field studies, Dust, Methodology, Land use, rangelands, mine storage facilities.

\section{Introduction}

44 Wind erosion is widespread across natural and anthropogenic surfaces and occurs 45 worldwide where wind speeds exceed the threshold velocity required to detach soil or 46 sediment particles and transport them. The susceptibility of a surface to wind erosion can 47 be measured in a variety of ways including field-based monitoring of wind regime and 48 sediment transport [1-2], using laboratory or field-based wind tunnels [3-5], portable wind 49 erosion facilities [6] and modelling [7-9]. Each approach has advantages and limitations [5] 50 and this paper focuses on the use of a field wind tunnel.

51 Despite the increasing variety of techniques available for studying wind erosion, wind 52 tunnels, which are one of the earliest approaches [10], are still very widely used. The 53 usefulness and validity of wind tunnels depends on them adequately simulating the natural 54 processes of wind and for this reason they have typically been constructed to be as large 55 as possible to minimize scaling effects [11]. Whilst fixed location, stationary wind tunnels used for aeolian research can be very large, for example the Chinese Academy of Sciences has a $38 \mathrm{~m}$ lab based tunnel [12], their limitation is that they are generally only used with artificial soil surfaces. In contrast, portable wind tunnels typically have an open floor, and can be moved around in the field to simulate wind erosion of surfaces in situ. Van Pelt et al. [5] provide a useful review of portable wind tunnels used in wind erosion research and highlight that although these tunnels are 'portable' they are often large (e.g. cross-section up to $1 \mathrm{~m}^{2}$ and length over $10 \mathrm{~m}$ ) and require considerable logistical support for deployment. Large portable tunnels also have the disadvantage of requiring space around the tunnel for locating generators, trucks, trailers and ancillary equipment.

In many situations it is difficult and expensive to deploy such large wind tunnels in the field due to physical limitations of; site access (e.g. unmade roads), steepness of slopes (e.g. on mine spoils), and cost of labour required to rig and operate the tunnel. Also, on vegetated field sites aerodynamic 'noise' is introduced because of difficulties in achieving a good seal between the soil surface and the tunnel [13]. The working section beneath large tunnels can also homogenise the effects of spatial variations in soil surfaces, such as changes in sediment size and soil crust characteristics [14]. Some small portable wind tunnels have been developed and successfully used in the field. For example the wind tunnel constructed by Gillette [15] had a small cross section of $150 \mathrm{~mm} \times 150 \mathrm{~mm}$ and length of 3 $\mathrm{m}$ and was used to determine threshold friction velocities on biological crusted soil surfaces 75 [16-17]. An alternative approach is the Portable In Situ Wind ERosion Lab (PI-SWERL). 76 The PI-SWERL differs from duct-type wind tunnels in that it uses rotating airflow within a $770.57 \mathrm{~m}$ diameter cylinder to generate shear stresses on the surface. Despite this 78 fundamental difference, the results from the PI-SWERL compare well with those from 79 conventional duct-type wind tunnels [18]. 
80 The present paper describes the development and testing of a new micro wind tunnel 81 (MWT) designed for field simulation of wind erosion on small plots. The MWT is a duct-type 82 design and is novel because it can be deployed by a single person on slopes ranging from 83 0-10 degrees. Three examples are provided to illustrate the application of the device 84 measuring the erodibility of rangeland and claypan soils, and of stockpiles at an iron ore 85 storage facility.

\section{Materials and Methods}

Numerous researchers have proposed practical and aerodynamic criteria to be met by the design of portable wind tunnels $[19,20]$. These design criteria are summarised by Maurer 90 et al. [13] as

- the tunnel must achieve wind speeds that reflect natural conditions;

- the tunnel should produce realistic aerodynamic flows within;

- the tunnel must be easy to transport, assemble and handle

and the criteria have been recently reviewed by Van Pelt et al. [5]. In addition, for wind erosion studies it is important that the full range of aeolian sediment transport processes (creep, saltation, suspension) can occur, and that saltating grains can be introduced at the upwind end of the working section to simulate the saltation impact process [20].

\subsection{Design and Construction}

The MWT has seven key components: a motor and tunnel wind velocity regulator, transition, working and exhaust sections, sediment trap, saltation injection tube and wind speed sensors (Figure 1). The motor is a $0.55 \mathrm{~kW}$ electric 240 -volt induction motor that turns a $280 \mathrm{~mm}$ axial fan. The motor creates suction through the tunnel generating a velocity range of $5-18 \mathrm{~m} \mathrm{~s}^{-1}$. Wind velocity is controlled via a calibrated baffle plate on the motor exhaust; complete blockage of the exhaust produces zero velocity whilst no blockage allows maximum velocity. Air is drawn into the tunnel through an opening $220 \times 50 \mathrm{~mm}$ which contracts over $250 \mathrm{~mm}$ to a cross section $100 \times 50 \mathrm{~mm}$ thus accelerating and stabilising the airflow. This stabilisation and organisation of airflow continues through the $1100 \mathrm{~mm}$ long transition section (aluminium box tube) downwind of which is a $1000 \mathrm{~mm}$ long working section. Within the working section the aluminium floor has been removed allowing direct contact between the wind and the soil surface. The top of the working section has a Perspex viewing window. Keyholes drilled in the top at distances of 100, 450 and $900 \mathrm{~mm}$ from the upwind end of the working section allow access for velocity measurement instruments (1 $\mathrm{mm}$ Dwyer pitot-static tubes) and are sealed with silicone plugs when not in use. Downwind of the working section is the $705 \mathrm{~mm}$ long exhaust section in which tunnel wind velocity is measured, wind transported sediment is subsampled via the sediment trap and the cross-section changes from rectangular to circular to 
118 allow connection to the induction motor. A manually operated flow bypass valve within the 119 exhaust section enables the operator to control when air is drawn through the tunnel. This 120 avoids the ramp up / ramp down wind speeds associated with the motor being turned on/off being drawn across the tested surface. When the flow bypass value is lowered, air is sucked from the roof within the exhaust section, avoiding flow over the working section. Once the motor has reached maximum revolution, the flow bypass valve can be raised redirecting suction (flow) to the tunnel inlet, ensuring desired wind speed is passed over the working section. The total tunnel footprint including all sections is $3050 \mathrm{~mm} \times 120 \mathrm{~mm}$. The generator and tunnel motor are connected via $5 \mathrm{~m}$ lengths of ducting (76 mm diameter) and can be positioned away from the operating tunnel. All equipment is contained in four boxes and transported (including the generator) in a standard box trailer $(1800 \times 1200 \mathrm{~mm})$.

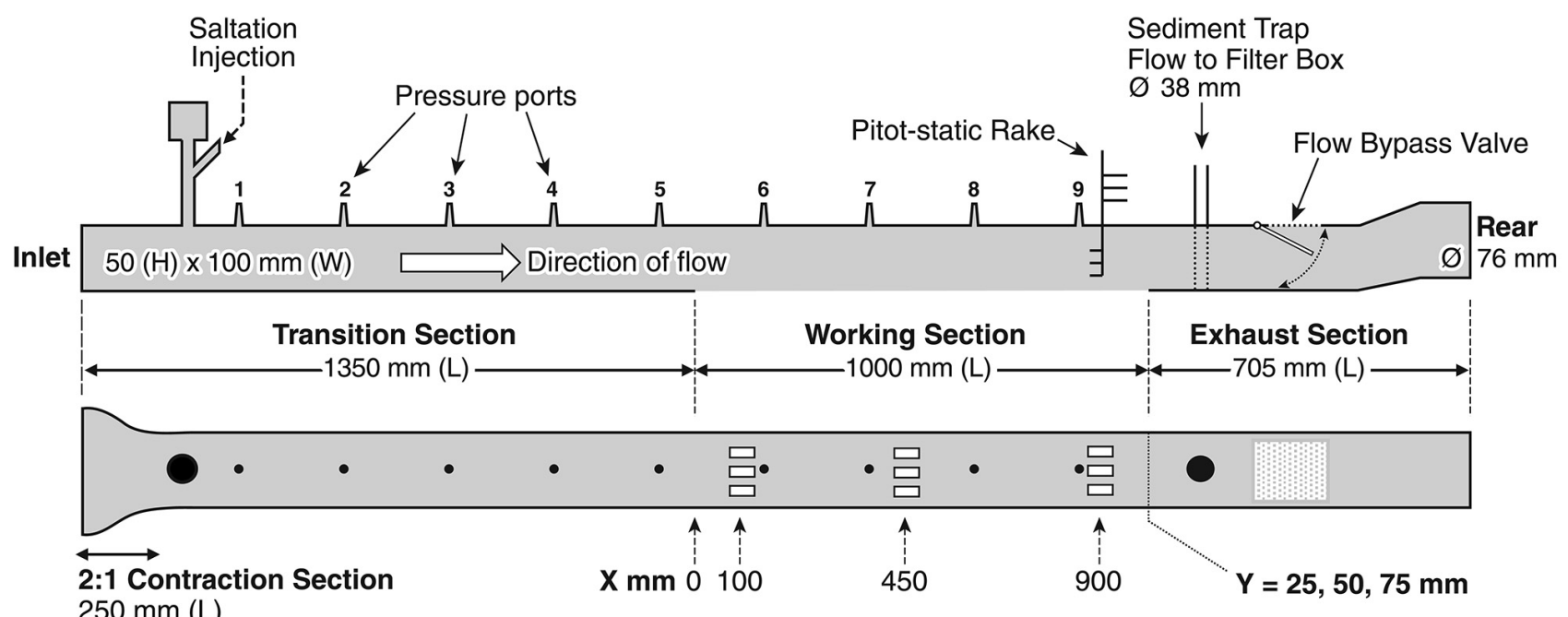

$50(\mathrm{H}) \times 220 \mathrm{~mm}(\mathrm{~W})$

Saltation Injection Tube

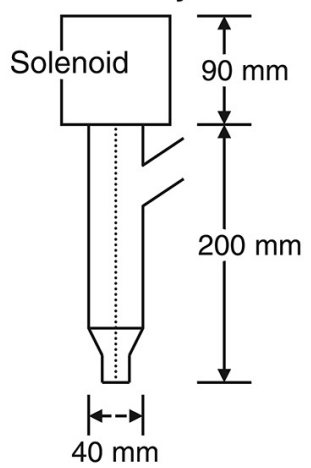

Induction Motor

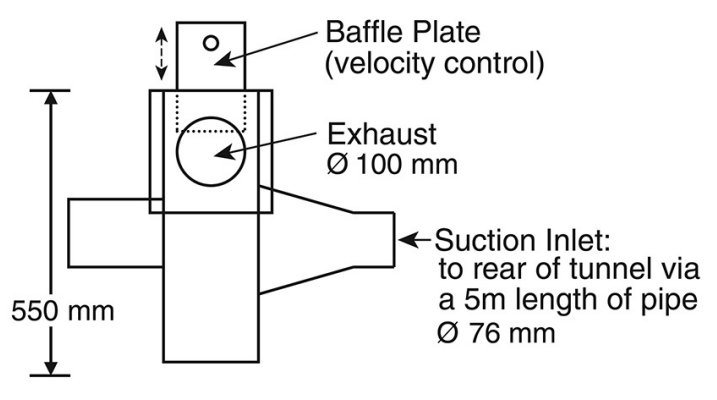

Sediment Filter Box

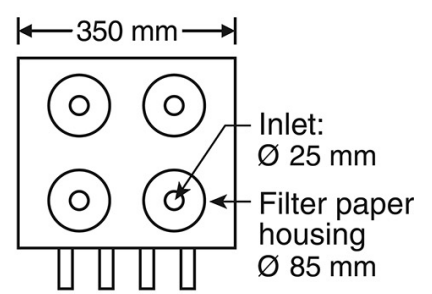

Fig. 1 Schematic diagram of the Micro Wind Tunnel (MWT) displaying the three sections (transition, working and exhaust) and velocity measurement options (pressure ports and pitot-static rake) present. The flow bypass valve enables air to be drawn through the tunnel from the suction induction motor attached at the rear. Sediment transported in the tunnel is subsampled at the sediment trap and collected on filter papers housed in the sediment filter box. 
138 a $40 \mathrm{~mm}$ diameter acrylic tube, positioned at the upwind end of the transition section, which 139 narrows to $2 \mathrm{~mm}$ diameter at the base. The injection tube can be opened or sealed using a 140 tapered stainless-steel rod controlled using a solenoid that lifts the rod $10 \mathrm{~mm}$ vertically. 141 The solenoid can be activated at the same time as the bypass valve in order to synchronise 142 saltation injection with the start of tunnel flow. Transported sediment is collected via a 143 vertical slot sampler $10 \mathrm{~mm}$ wide and $50 \mathrm{~mm}$ high. This is located on the centre line of the 144 tunnel and is used to sub sample (10\%) of the sediment-laden tunnel airflow. Air from the 145 sediment sampler is drawn vertically through a $38 \mathrm{~mm}$ hose to the sediment filter box which 146 houses $125 \mathrm{~mm}$-diameter glass-fibre filter papers with $0.1 \mu \mathrm{m}$ pores.

147 For any one run, wind speed within the tunnel can be measured simultaneously at three 148 different locations using pressure transducers connected to pitot-static tubes or roof 149 mounted pressure ports or a combination of the two. The $1 \mathrm{~mm}$ dynamic port Dwyer pitot150 static tubes can be positioned in a streamwise array at $100 \mathrm{~mm}, 450 \mathrm{~mm}$ and $900 \mathrm{~mm}$ from 151 the upwind end of the working section along the centre line. Alternatively, at each of these 152 locations, they can be arranged crosswise on the centre line and $25 \mathrm{~mm}$ from each wall (i.e. 1533 equidistance measurements cross-flow). A pitot-static tube can also be located within the 154 sediment trap at the downwind end of the tunnel. The pressure ports are fitted inside the 155 tunnel, flush with the roofline, and located along the centre line at $300 \mathrm{~mm}$ intervals in the 156 transition section and $200 \mathrm{~mm}$ intervals in the working section (nine in total). The most 157 common field sampling configuration is one pressure transducer connected to a pitot tube 158 at $900 \mathrm{~mm}$ upwind at the cross sectional mid-point, one pressure transducer connected to a 159 pitot tube in the sediment sampler and the last pressure transducer connected to opposite 160 end roofline pressure ports (i.e. pressure port numbers one and nine). Where more than 161 three velocity measurements are required to characterise three dimensional flow structures, 162 the tunnel can be run multiple times at a fixed reference velocity with the pressure 163 transducers in different configurations. Data can be made dimensionless by relating all 164 measurements to a fixed reference point. Temperature of the tunnel airflow and barometric 165 air pressure are measured every second and averaged over 1 minute to enable the 166 calculation of air density.

\section{$167 \quad 2.2$ Airflow Measurements}

168 A range of tests were undertaken to characterise: a) the range of tunnel wind velocities 169 achieved within the tunnel, b) the uniformity of airflow and c) to develop an alternative 170 technique of calculating $u_{*}$ other than from logarithmic velocity profiles.

171 Tunnel wind velocity is controlled by raising or lowering the baffle plate on the induction 172 motor exhaust (Figure 1). To determine the relationship between baffle position and tunnel 173 velocity the MWT was run as it would be in the field (i.e. with filters in place) but over a 174 smooth control surface (4 mm ABS plastic sheet, 'glassy' side up). Each baffle position was 175 replicated 19 times and the MWT was run for one minute per replicate. Wind speed was 176 measured using the pitot-static tubes and roof mounted pressure ports. Each baffle 177 position created a different wind speed ranging from 5-18 $\mathrm{m} \mathrm{s}^{-1}$ with excellent reproducibility 178 (all standard errors lie within $+/-0.002 \mathrm{~m} \mathrm{~s}^{-1}$ of the mean value) (Figure 2). 

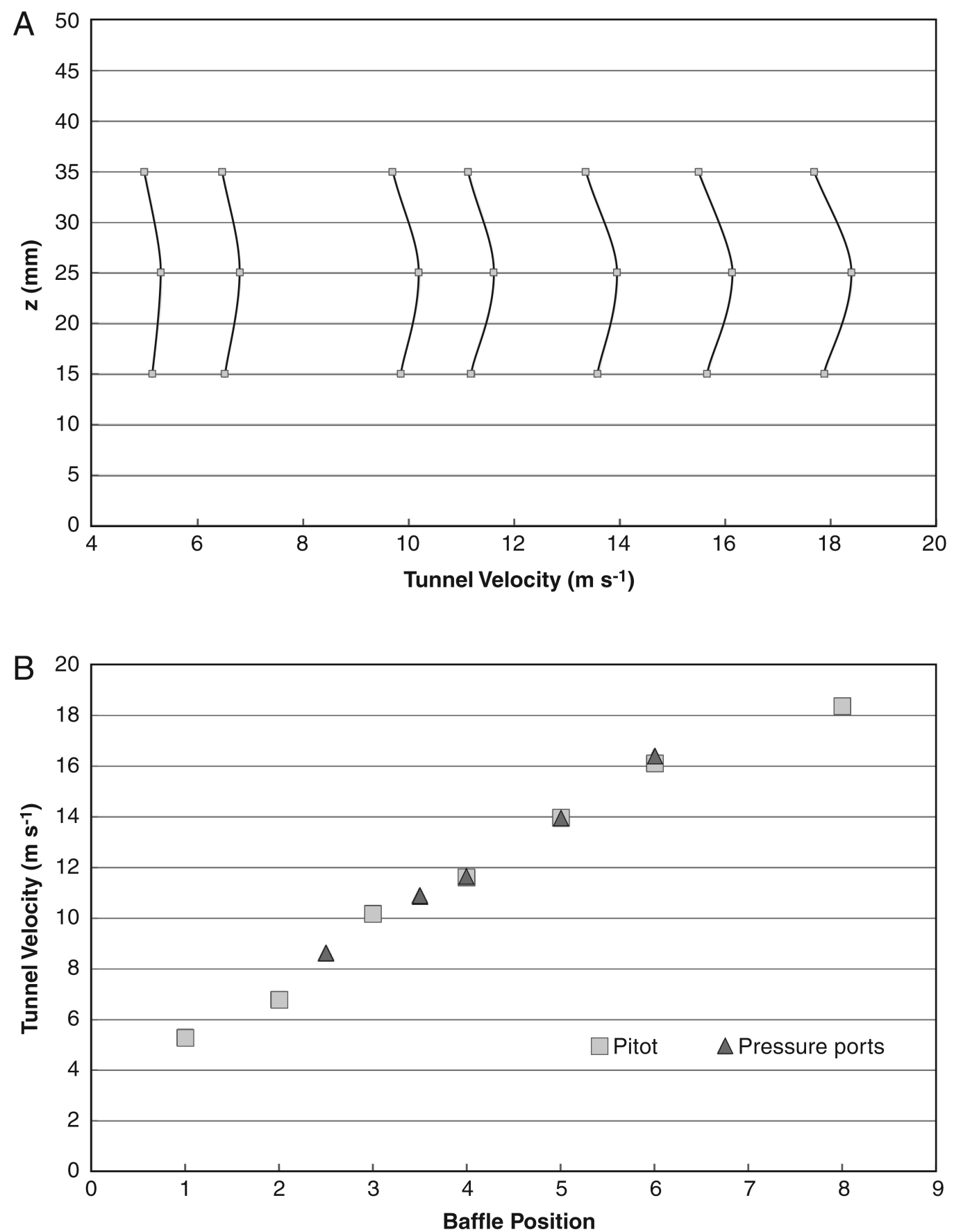

180 Fig. 2 Airflow velocity $\left(\mathrm{m} \mathrm{s}^{-1}\right)$ is determined by the position of the exhaust baffle. A) Velocity profiles measured 181 with pitot-static tubes over a smooth test surface. Measurements made with a pitot $\operatorname{rake}$ at $\mathbf{x}=900, \mathbf{y}=50, \mathrm{z}=15$, 18225 and 35. SE included (19 reps/baffle position). B) Comparison of airflow velocities ( $\mathrm{m} \mathrm{s}^{-1}$ ) measured using pitot183 static tubes (squares) at $x=900, y=50, z=25$ (SE included) and pressure port measurements at $x=200$ and 900 , $y=50, z=50$ (SE included). All testing conducted on the same smooth surface. All standard errors lie within $+/-$ $0.002 \mathrm{~m} \mathrm{~s}^{-1}$ of the mean values

187 Ideally a wind tunnel should produce uniform airflow across the tunnel and develop a 188 logarithmic profile of wind velocity with height. To test these, with the baffle in position 2.5, wind speed was measured at $25 \mathrm{~mm}, 50 \mathrm{~mm}$ and $75 \mathrm{~mm}$ distance across the tunnel (y axis) 
at 9 different heights $(5,10,15,20,25,30,35,40,45 \mathrm{~mm} ; z$ axis $)$ and located at $100 \mathrm{~mm}$, $450 \mathrm{~mm}$ and $900 \mathrm{~mm}$ from the upwind end of the working section (x axis). This approach provides a grid of 27 velocity measurements at each downwind location and shows how cross-flow uniformity varies with distance down the working section. If all the measurements had been taken simultaneously the instrumentation would have blocked the airflow in the tunnel and set up secondary airflow patterns, so, given the uniformity of wind speeds indicated in Figure 2, measurements were taken at 3 locations at a time for the same baffle position and combined to create the data grid. These tests were repeated over 199 200 three artificial surfaces, one smooth (ABS plastic as above), one of medium roughness (40 grit sand paper), and one rough (10 $\mathrm{mm}$ diameter marbles protruding $2 \mathrm{~mm}$ above the test bed).

All surfaces within the tunnel are sources of drag, and the cross-sectional contour plots indicate that changes in floor roughness create the greatest changes in the flow symmetry 203 (Figure 3). As floor roughness increases, flow lines compress near the floor surface. Figure 204 3 also indicates there is a slight surface imperfection in the top left hand corner where the 205 206 207 208 209 Perspex working section ceiling is affixed. This has changed the flow symmetry slightly with slower flow along the left side. Despite this, the flow in the tunnel reflects what would be expected in a rectangular duct which is a fully developed flow. The length of the tunnel means this fully developed flow is also turbulent in nature and there is no logarithmic velocity profile as expected in larger wind tunnels.
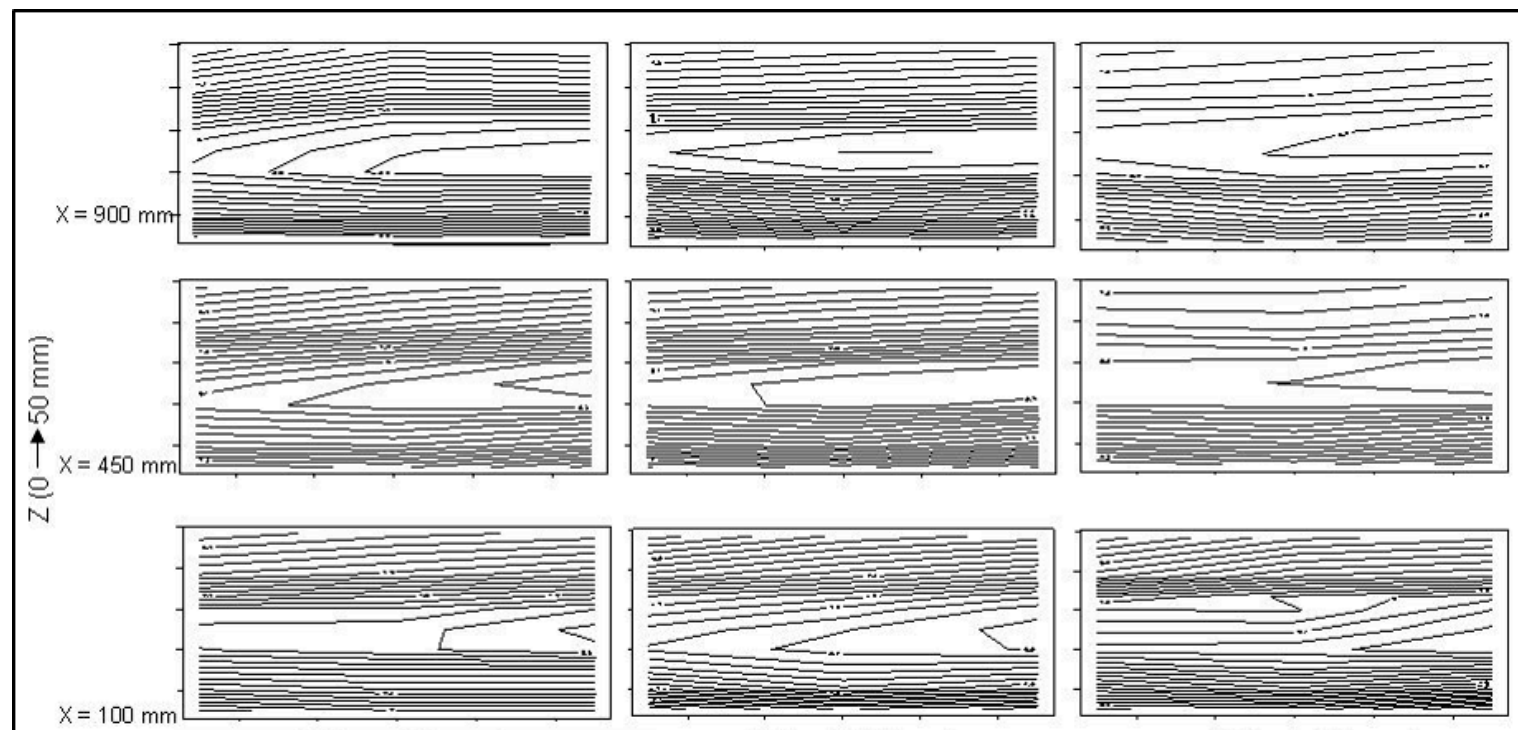

$\mathrm{Y}(\mathrm{O} \rightarrow 100 \mathrm{~mm})$

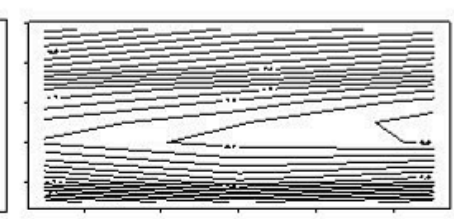

$\mathrm{Y}(\mathrm{0} \rightarrow 100 \mathrm{~mm})$

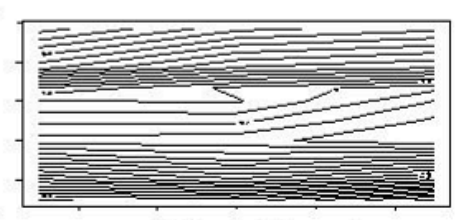

Smooth surface

Medium surface

$\mathrm{Y}(\mathrm{O} \rightarrow 100 \mathrm{~mm})$

Rough surface

212 Fig. 3 Contour plots of airflow velocity $\left(0.2 \mathrm{~m} \mathrm{~s}^{-1}\right.$ intervals) for smooth, medium and rough test surfaces showing 213 the cross-sectional profile of the tunnel at $\mathbf{1 0 0 , 4 5 0}$ and $900 \mathbf{~ m m}$ from the upwind end of the working section.

214 Airflow direction is away from the reader 
216 As the MWT is a duct with a fully developed flow the shear stress and the friction velocity

217 are calculated by measuring the pressure gradient not by the traditional approach of using

218 logarithmic velocity profiles [5, 15, 19, 20]. Pressure drop along the length of a duct is well

219 understood within fluid mechanics [21, 22]. The approach taken here is to partition the

220 contribution that an open floor (one wall of the duct) has on the total duct pressure

221 gradients in order to calculate the shear stress and the friction velocity on that surface. The

222 following describes the approach taken.

223 Internal flow within a duct is constrained by bounding walls and the viscous effect which

224 permeates the entire flow. Inviscid flow enters the duct and viscous boundary layers flow

225 downstream retarding the axial flow $u(y, z)$ at the wall, thereby accelerating the centre of the

226 flow to maintain the incompressible continuity requirement [21].

$$
Q=\int_{A} u(y, z) d A=\text { constant }
$$

229

Where $Q$ is volume flow, $u(y, z)$ is flow velocity and $A$ is cross sectional area. At a finite 230 distance from the entrance the boundary layers merge and the inviscid core disappears.

231 The duct flow then is entirely viscous and the axial velocity adjusts until it is fully developed.

232 The distance $(x)$ downstream that this occurs is referred to as the entrance length $\left(L_{e}\right)$.

233 Downstream of $x \geq L_{e}$ the velocity profile $u(y, z)$ is constant, wall shear is constant and

234 pressure drops linearly with $x$ for either laminar or turbulent flow. Dimensional analysis

235 indicates the Reynolds number $\left(R_{e}\right)$ is the only parameter affecting entrance length $L_{e} . R e_{m}$ 236 is the Reynolds number for the MWT and calculated by

$$
R e_{m}=\frac{\rho U}{v} D_{h}
$$

$$
=\omega D_{h}
$$

239 where $U$ is the average flow velocity, $\rho$ is the density of air, $v$ is the viscosity of air, $D_{h}$ is the 240 hydraulic diameter, and $\omega$ is the scaled flow velocity. In a rectangular duct, the hydraulic

241 diameter is determined as

$$
D_{h}=\frac{2 x \text { area }}{\text { width }+ \text { height }}
$$

244 The MWT has Reynolds numbers ranging from 26,500 $<R e_{m}<80,000$ (i.e. fully turbulent 245 flow) [22]. In ducts with turbulent flows, the boundary layers grow faster and $L_{e}$ is relatively 246 short:

$$
\frac{L_{\varepsilon}}{D_{h}} \approx 4.4 R e_{m}^{\frac{1}{6}}
$$


248 Therefore whilst the MWT does not support a log profile, the entrance length $\left(L_{e}\right)$ effect is 249 restricted within the transition section of the tunnel leaving the fully developed flow region to 250 occur within the working section (Figure 1). This is important because it is in the working 251 section that a developed velocity profile $u(y, z)$ needs to occur if changes in surface 252 roughness are to be determined.

253 In larger wind tunnels the surface roughness is calculated from the wind profile. However, 254 the micro wind tunnel does not support a log profile, thus an alternative technique for 255 calculating $u_{*}$, the friction velocity, is required. The friction velocity $\left(u_{*}\right)$ is frequently used to 256 measure the wind speed required to initiate sediment movement.

257 The integral momentum method [23 in 24] is used here to calculate $u_{*}$. This paper shows 258 that the friction velocity can be determined by measuring pressure gradients and using 259 integral momentum balance. Theoretically, in a fully developed duct flow, the integral 260 momentum balance is:

$$
\int_{P} \rho u_{*}^{2} d P=-A \frac{d p}{d x}
$$

262 where $u_{*}$ is the friction velocity, $\rho$ is air density, $\rho u_{*}^{2}$ is the drag on the surface of the duct, $P$ 263 is the perimeter of the duct, $d P$ is increment of the perimeter, $A$ is the cross-sectional area 264 of the duct and $\frac{d p}{d x}$ is the stream-wise pressure gradient. Therefore, in a rectangular duct of 265 height $Z$ and breadth $Y$ :

$$
2(Y+Z) u_{* a}^{2}=-\frac{Y Z}{\rho} \frac{d p}{d x}
$$

267 where $u_{*_{\alpha}}$ is an area-weighted average friction velocity for all surfaces around the tunnel 268 circumference. The turbulence and secondary flow within the duct as documented by 269 Schetz and Allen [22] act to equalise the shear stress across the perimeter of the duct. 270 Thus, it is possible to partition the friction velocity to the various surfaces, hence the floor 271 contributes a length $Y$ to this average and the sides and roof together contribute a length $272(2 Z+Y)$. Consequently:

$$
2(Y+Z) u_{* a}^{2}=Y u_{* f}^{2}+(2 Z+Y) u_{* s}^{2}
$$

275 where $u_{*_{f}}$ is the friction velocity for the rough floor and $u_{*_{s}}$ is the friction velocity for the 276 smooth sides and roof. Equating Equations 7 and 8 gives:

$$
Y u_{* f}^{2}+(2 Z+Y) u_{* s}^{2}=-\frac{Y Z}{\rho} \frac{d p}{d x}
$$


278 Determining the friction velocity for the rough floor $\left(u_{*_{f}}\right)$ can therefore be inferred from

279 measurements of the pressure gradient $\left(\frac{d p}{d x}\right)$ by re-arranging Equation 8 as:

280

$$
u_{* f}^{2}=-\left(\frac{2 Z}{Y}+1\right) u_{* s}^{2}-\frac{Z}{\rho} \frac{d p}{d x}
$$

283 Now $u_{*_{s}}$ can be determined by noting that when $u_{*_{f}}=u_{*_{s}}$, Equation 8 becomes:

$$
2(Z+Y) u_{* a}^{2}=(2 Z+2 Y) u_{* s}^{2}
$$

285 Equating Equations 7 and 11 gives:

286

$$
u_{* s}^{2}=-\left.\frac{Y Z}{2(Z+Y) \rho} \frac{d p}{d x}\right|_{s}
$$

287 Where $\left.\frac{d p}{d x}\right|_{s}$ denotes the pressure gradient when all four surfaces are smooth. Hence, $u_{*_{f}}$ 288 can be related to current pressure gradient $\left(\frac{d p}{d x}\right)$ and the smooth pressure gradient $\left(\left.\frac{d p}{d x}\right|_{s}\right)$ by:

$$
u_{* f}^{2}=-\frac{z}{\rho}\left[\frac{d p}{d x}-\left.\frac{(2 Z+Y)}{2(Z+Y)} \frac{d p}{d x}\right|_{s}\right]
$$

290 Finally, the surface roughness $\left(\mathrm{Z}_{0}\right)$ can be estimated from the central flow characteristics of 291 the duct:

292

$$
z_{0} \approx \frac{25 \times 10^{-8}}{\exp \left(\frac{k u_{c}}{u_{*}}\right)}
$$

293 where $u_{c}$ is the measured velocity in the centre of the duct $(\mathrm{z}=25 \mathrm{~mm})$ and $\mathrm{k}=$ von

294 Karman's constant (0.4).

295 These theoretical workings were tested by measuring the pressure gradient for the 296 transition and working sections of the tunnel over three test surfaces (under both transition 297 and working sections). These three surfaces are; smooth (4 mm ABS plastic, 'glassy' side 298 up), medium (213 micron sand spray-glued to PVC) and rough (bubble-wrap with bubble 10 $299 \mathrm{~mm}$ diameter, $5 \mathrm{~mm}$ high). Results in Table 1 show that as the test surface roughness 300 increased, so did $u_{* f}$, indicating that the pressure gradient method is sensitive to scaling 301 issues within the MWT. This increases confidence that drag coefficient can be partitioned. 302 
Table 1 Flow descriptors for the MWT calculated using the pressure gradient method (Raupach et al. 2006) for the flow on the tunnel floor. Wind speeds measured using the roof mounted pressure ports (pressure port measurements at $x=200$ and $900, y=50, z=50$ ).

\begin{tabular}{|l|l|l|l|l|}
\hline $\begin{array}{l}\text { Tunnel speed } \\
\mathrm{m} \mathrm{s}^{-1}\end{array}$ & Test surface & $\begin{array}{l}\text { Coefficient of } \\
\text { drag (unitless) }\end{array}$ & $\mathrm{u}_{*}\left(\mathrm{~m} \mathrm{~s}^{-1}\right)$ & $\mathrm{z}_{\mathrm{o}}(\mathrm{mm})$ \\
\hline 6.8 & Smooth & 0.0023 & 0.32 & 0.006 \\
\hline 6.8 & Medium & 0.0034 & 0.40 & 0.026 \\
\hline 6.8 & rough & 0.0059 & 0.52 & 0.139 \\
\hline 11.6 & Smooth & 0.0021 & 0.54 & 0.004 \\
\hline 11.6 & Medium & 0.0034 & 0.68 & 0.027 \\
\hline 11.6 & rough & 0.0056 & 0.86 & 0.117 \\
\hline
\end{tabular}

The data in Table 1 compare well with $u_{*}$ values of $0.35 \mathrm{~m} \mathrm{~s}^{-1}\left(\mathrm{U}=6.8 \mathrm{~m} \mathrm{~s}^{-1}\right)$ and $0.72 \mathrm{~m} \mathrm{~s}^{-1}$ $\left(\mathrm{U}=11.6 \mathrm{~m} \mathrm{~s}^{-1}\right)$ obtained by Shao and Raupach [25] who tested on a bed of $200 \mu \mathrm{m}$ sand using a large portable wind tunnel. This result suggests that the MWT produces comparable surface drag for the wind speeds in the tunnel. Figure 4 shows the relationship between tunnel velocity and friction velocity for the MWT.

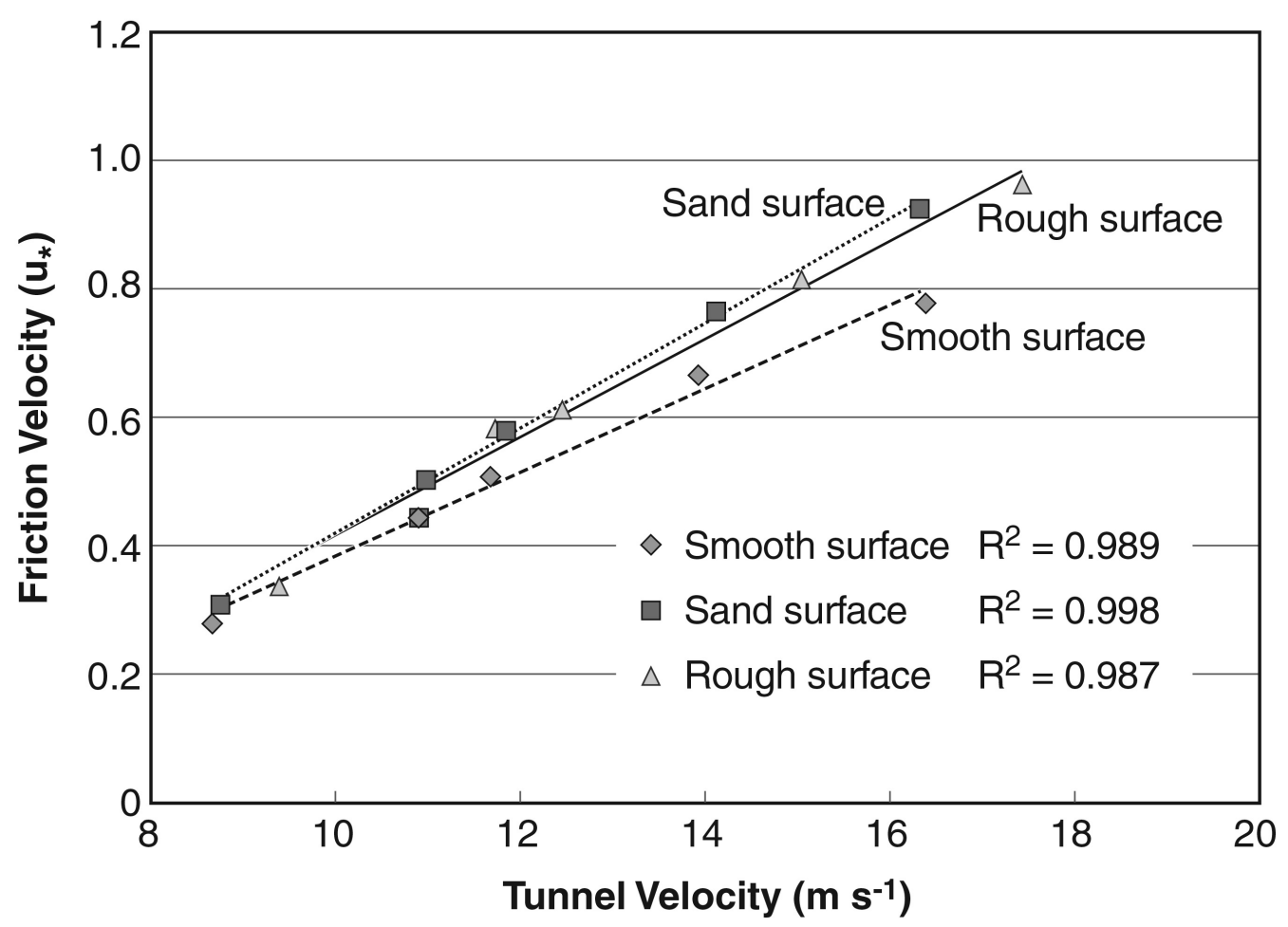

Fig. 4 Relationships between the tunnel velocity and $u_{*}$ for each of the three tested surfaces $(\operatorname{smooth}(\mathrm{z}<0.01 \mathrm{~mm})$, medium $(\mathrm{z} \sim 0.1 \mathrm{~mm})$ and rough $(\mathrm{z} \sim 2 \mathrm{~mm}))$. Wind speeds measured using the roof mounted pressure ports (pressure port measurements at $x=200$ and $900, y=50, z=50$ ). All standard errors lie within $+/-0.002$ of the mean values 


\section{$321 \quad 2.3$ Saltation injection, collection efficiency and operation procedures}

322 Saltation injection is used in a wind tunnel to achieve saturated saltation flow. In the field 323 saturated saltation will develop over much longer distances than can be reproduced in the 324 working sections of portable wind tunnels $[20,25]$. Saltation sands should therefore be 325 delivered at a flux rate sufficient to produce saltation rates observed in the field, and have 326 known physical properties (size, chemical composition).

327 Commercially available sand with a unimodal size of 213 microns and $99 \%$ quartz content 328 is used in the MWT saltation injection system. Without the tunnel operating (tunnel velocity $329=0 \mathrm{~ms}^{-1}$ ) the saltation flux rate is $6.1 \pm 0.1 \mathrm{~g} \mathrm{~m}^{-1} \mathrm{~s}^{-1}$. As the tunnel airflow velocity increases 330 (tunnel velocity $=5-16.1 \mathrm{~ms}^{-1}$ ) so too does the saltation flux rate, ranging from 7.5-10.8 g $331 \mathrm{~m}^{-1} \mathrm{~s}^{-1}$ (Figure 5). Saltation flux rates are slightly higher than those reported by Pietersma et 332 al. [26] who had an adjustable saltation feed rate of 0.25-6.6 $\mathrm{g} \mathrm{m}^{-1} \mathrm{~s}^{-1}$, but lower than Van 333 Pelt et al., [5] who had an adjustable saltation feed rate of $10-30 \mathrm{~g} \mathrm{~m}^{-1} \mathrm{~s}^{-1}$. The range of 334 saltation flux rates for the MWT is within the variability reported for other wind tunnels and 335 therefore differences considered inconsequential.

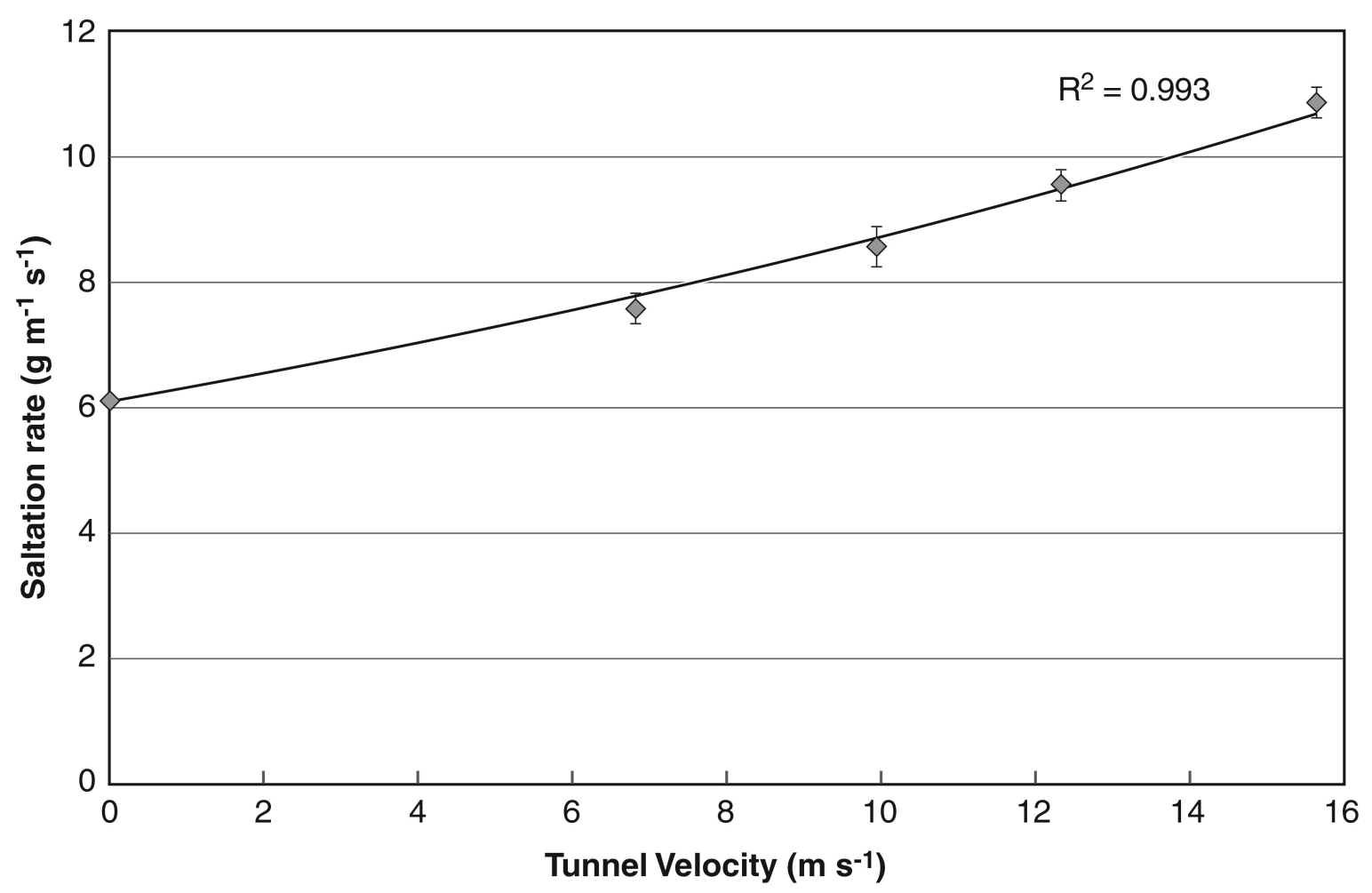

Fig. 5 Saltation flux rate is $6.1 \mathrm{~g} \mathrm{~m}^{-1} \mathrm{~s}^{-1}$ with no tunnel flow but increases $\left(7.5-10.8 \mathrm{~g} \mathrm{~m}^{-1} \mathrm{~s}^{-1}\right)$ as tunnel velocity increases. Each velocity was replicated five times measured using pitot-static tubes at $x=900, y=50, z=25$ and all standard errors lie within $+/-0.07$ of the mean values

341 The collection efficiency of the sediment sampler was tested by adding a known amount of 342 saltation sand. The sampler inlet has a cross-section of $10 \times 50 \mathrm{~mm}$ representing $10 \%$ of 
343 the cross-sectional area of the tunnel. For four wind speeds (each repeated five times) 30 $344 \mathrm{~g}$ of saltation sand was added via the saltation injection system at the start of the one 345 minute run (using a smooth test bed). Assuming that the sediment sampler is $100 \%$ 346 efficient, $3 \mathrm{~g}$ of sediment should be collected at the end of each run. The ratio of collected sediment to that expected shows that on the smooth test surface, the sampling efficiency was greater than $95 \%$ for wind speeds higher than $10 \mathrm{~ms}^{-1}$ but dropped to $85 \%$ at lower wind speeds (Figure 6). A change in trapping efficiency with wind speed is commonly observed in semi-isokinetic samplers [27]. On rough surfaces the expectation is that sediment will be trapped by roughness elements reducing the amount of sediment reaching the sampler. Understanding the trap efficiency means that the storage potential of different surfaces can be estimated [24].

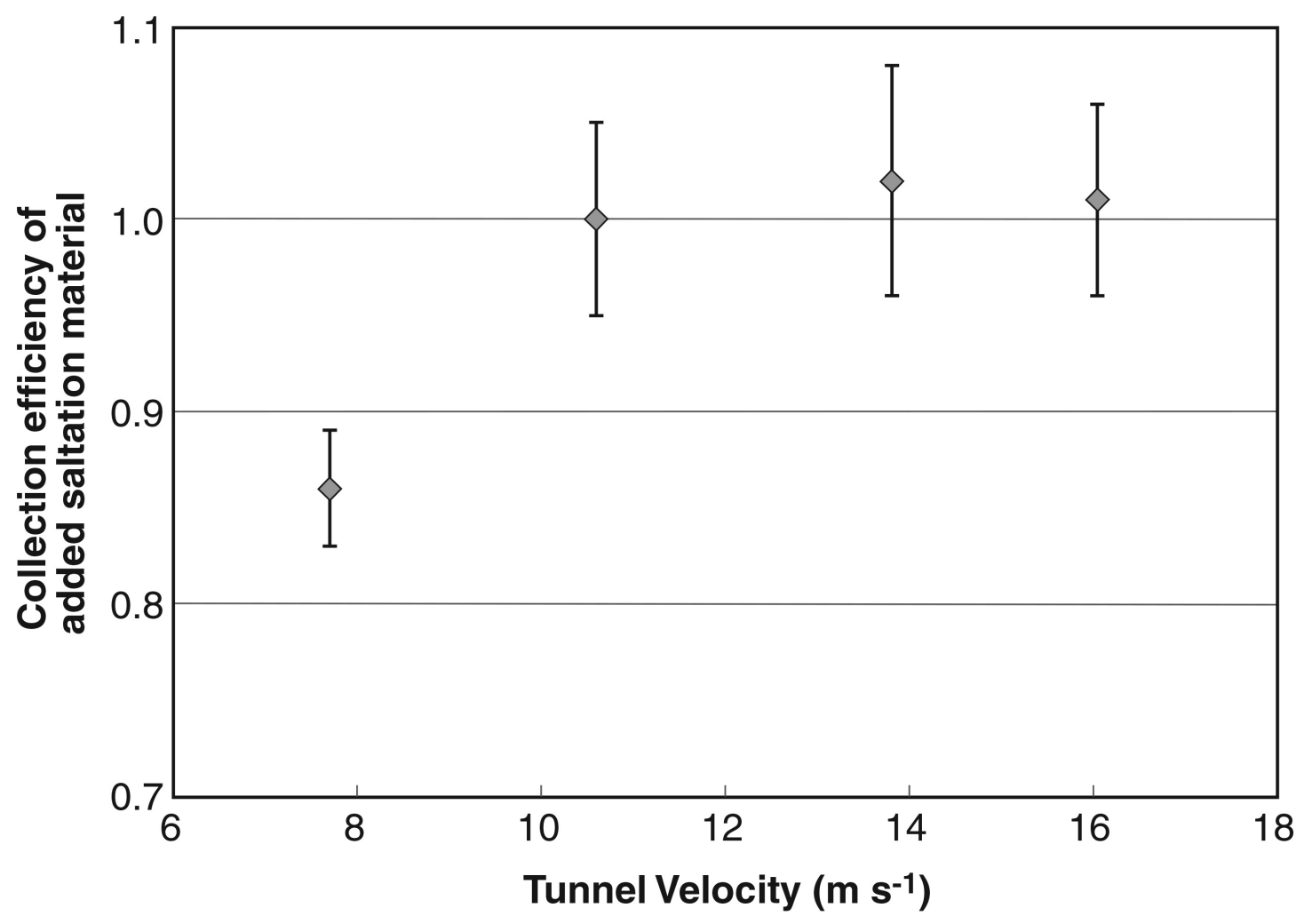

Fig. 6 Collection efficiency of the sediment sampler indicates that over a smooth test surface the tunnel is very efficient at collecting the expected $10 \%$ sediment flow released in the tunnel at wind speeds greater than $10 \mathrm{~m} \mathrm{~s}$. The tunnel under samples at tunnel velocities less than $8 \mathrm{~m} \mathrm{~s}^{-1}$ (baffle position 2). Each velocity was replicated five times measured using pitot-static tubes within the tunnel flow at $x=900, y=50, z=25$ and sediment trap line. All standard errors lie within $+/-\mathbf{0 . 0 5}$ of the mean values

Operating the MWT uses two approaches to saltation impact. The first approach relies on any naturally-available, loose, erodible material to act as a saltation source. Wind-removed sediment is collected on $125 \mathrm{~mm}$-diameter glass-fibre filter paper with $0.1 \mu \mathrm{m}$ pores, and 364 weighed. Sediment flux $(\mathrm{Q})\left(\mathrm{g} \mathrm{m}^{-1} \mathrm{~s}^{-1}\right)$ with no added saltation material is calculated as: 


$$
\mathrm{Q}=\frac{\text { mass }}{\left[0.01 \mathrm{~m}^{2} \times 60 \mathrm{~s}\right]}
$$

366

The second approach uses the addition of saltation material as described above to initiate the breakdown and removal of fine sediments through abrasion process. Saltation induced sediment flux $\left(Q_{\mathrm{SI}}\right)\left(\mathrm{g} \mathrm{m}^{-1} \mathrm{~s}^{-1}\right)$ is calculated as:

$$
\mathrm{Q}_{\mathrm{SI}}=\frac{[\mathrm{mass}-3 g]}{\left[0.01 \mathrm{~m}^{2} \times 60 \mathrm{~s}\right]}
$$

where mass is the weight $(\mathrm{g})$ of sediment collected on the filter paper and $0.01 \mathrm{~m}^{2}$ is the footprint of the MWT working area. This equation assumes that all the sediment introduced at the upwind end reaches the sediment sampler at the downwind end. This is a reasonable assumption for a smooth surface with no storage capacity. As highlighted above rough surfaces can trap sediments and there is potential to use the MWT to increase the understanding of this however it will not be explored further in this paper. To identify the susceptibility of a surface to abrasion, the ratio of $Q_{\mathrm{si}}: Q$ is used to describe the saltation entrainment ratio, quantifying how much more sediment was lost with the addition of saltation sand. The higher the number the greater impact of the saltation sands.

The use of a range of wind speeds on all surfaces provides an indication of how sediment flux changes with wind speed. Comparison between the surfaces requires a standard wind speed to act as a default comparison. The chosen wind speed was $\mathrm{u}=9 \mathrm{~m} \mathrm{~s}^{-1}$ as this typically causes sediment entrainment in the field $[28,29]$.

\subsection{Summary of development and calibration}

The MWT has been shown to produce velocities ranging from 5 to $18 \mathrm{~m} \mathrm{~s}^{-1}$ with high reproducibility. Wind velocities are laterally uniform $\left(+/-0.2 \mathrm{~m} \mathrm{~s}^{-1}\right)$ and values of $u_{*}$ at the tunnel bed (calculated using the integral momentum method) are comparable with those from larger tunnels where logarithmic, profiles can be developed [25,5]. To account for the variability in the saltation feed rate as velocity increases, known amounts of saltation sediment were used for all runs. A high collection efficiency ( $>85 \%)$ was reported across a range of tunnel velocities. The MWT therefore achieves the three fundamental wind tunnel design critieria proposed by Maurer et al., [13] of, producing wind speeds and aerodynamic flows that reflect natural conditions, along with being easy to transport, assemble and operate. 
400 The second half of this paper provides three contrasting examples of where the MWT has 401 been used in field research in order to illustrate the practicality of its use.

402

\subsection{Wind erosion of rangeland soils}

404 A field study was undertaken in semi-arid rangelands near Longreach, Queensland, 405 Australia to assess the impact of different stocking pressures from cattle and sheep grazing 406 on soil erodibility to wind [30]. Wind erosion simulations were conducted along a grazing 407 gradient (from high to low) leading away from a stock watering point; following the design of 408 Pickup [31]. Field experiments were conducted on two soil types, a cracking clay soil

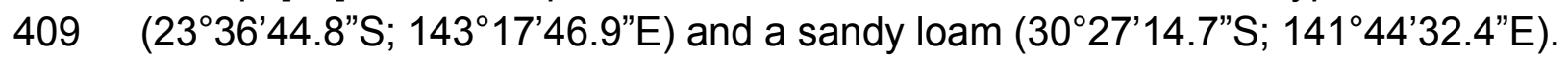

410 Both sites were vegetated with annual and perennial grasses. As the focus of the study 411 was upon soil erodibility (rather than the protection to soils afforded by vegetation) it was 412 important to exclude grasses from the wind tunnel simulation sites. The MWT was highly 413 suitable to this application because its small footprint could fit between the grass clumps 414 (Fig. 7). This project would not have been feasible with a conventional field wind tunnel, 415 because grasses could not have been excluded from the large working section of such a 416 tunnel.

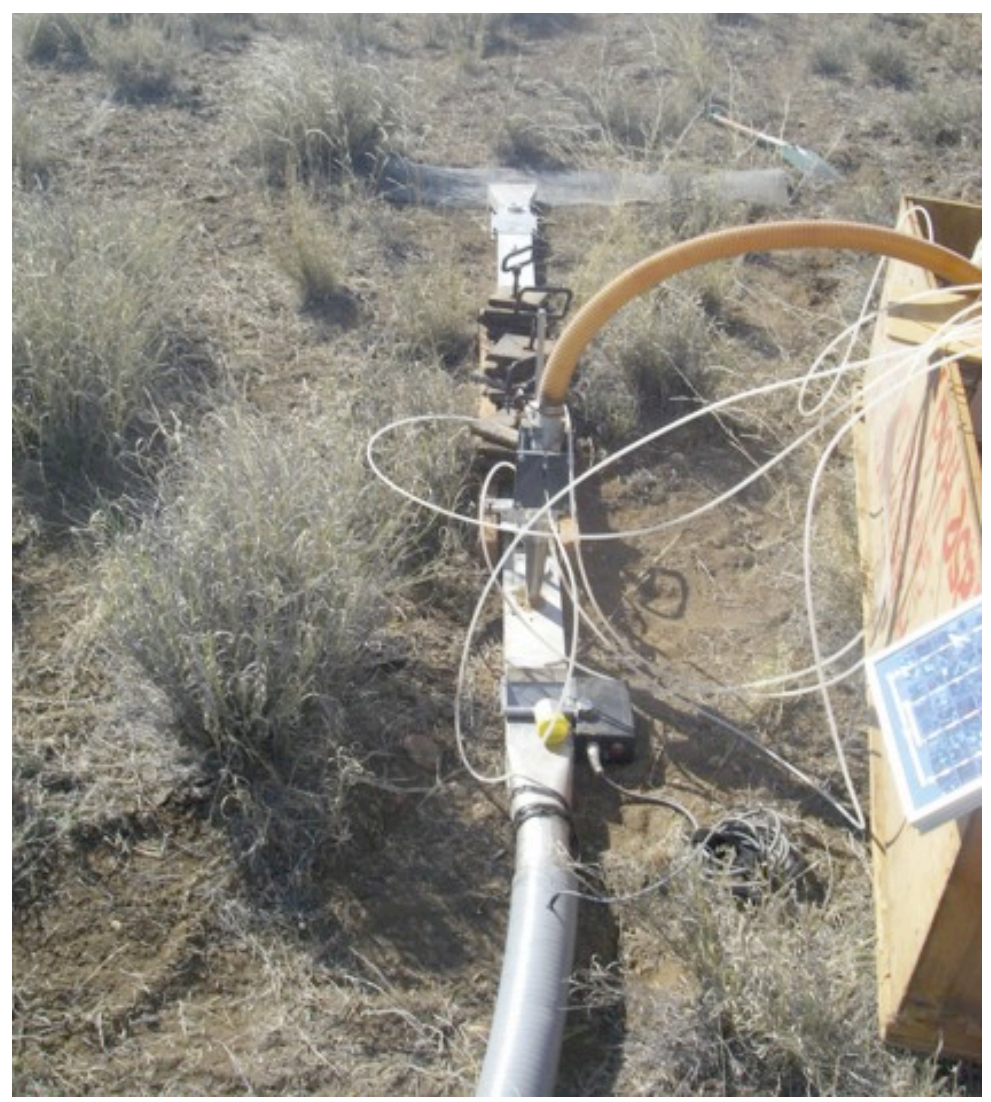

418 Fig. 7 The micro wind tunnel was highly suitable to deployment in a grassed rangeland site because its small 419 footprint could fit between grass clumps 
420 Sediment flux was measured along the grazing gradient using the MWT, but only two points 421 along this transect are reported here. The highest stocking rate and soil surface 422 disturbance zone was closest to the watering point and a low stocking rate and disturbance 423 zone was $2000 \mathrm{~m}$ from the watering point.

Table 2 Measured sediment flux $\left(\mathrm{g} / \mathrm{m}^{2} / \mathrm{s}\right)$ at two disturbance zones on two soil types using one MWT wind speed, $\mathrm{U}$ $=9 \mathrm{~m} \mathrm{~s}^{-1}$. $Q$ is sediment flux with only wind blowing across soil surface. $Q_{S I}$ is the sediment flux with saltation

\begin{tabular}{|l|l|l|l|l|}
\cline { 2 - 5 } \multicolumn{1}{c|}{} & \multicolumn{4}{c|}{ Sediment flux $\left(\mathrm{g} / \mathrm{m}^{2} / \mathrm{s}\right)$} \\
\cline { 2 - 5 } & \multicolumn{2}{c|}{ Clay site } & \multicolumn{2}{c|}{ Sandy loam site } \\
\cline { 2 - 5 } & $\begin{array}{l}\text { High } \\
\text { disturbance } \\
\text { zone }\end{array}$ & $\begin{array}{l}\text { Low } \\
\text { disturbance } \\
\text { zone }\end{array}$ & $\begin{array}{l}\text { High } \\
\text { disturbance } \\
\text { zone }\end{array}$ & $\begin{array}{l}\text { Low } \\
\text { disturbance } \\
\text { zone }\end{array}$ \\
\hline Without saltation added (Q) & 3.35 & 0.04 & 9.59 & 2.64 \\
\hline With saltation added (Q & 5.66 & 0.31 & 13.47 & 3.39 \\
\hline $\begin{array}{l}\text { Saltation entrainment ratio } \\
\left(Q_{\mathrm{SI}}: \mathrm{Q}\right)\end{array}$ & $\times 1.7$ & $\times 7.8$ & $\times 1.4$ & $\times 1.3$ \\
\hline
\end{tabular}

429 Three results of the MWT simulations are shown in Table 2.

430 1. Overall wind erosion rates, measured as sediment fluxes (Q), are higher on sandy loam 431 soils than clay soils; confirming the widely reported result that increasing the sand content 432 of soils increases their erodibility [32].

433 2. Disturbance of soil surfaces increases sediment fluxes on both soils but the relative 434 impact is much greater on the clay soil than on the sandy loam soils. This suggests that 435 clay soils are more vulnerable to increased stocking rates than sandy soils.

436 3. If saltation sands are present in the windflow sediment fluxes are increased to a much 437 greater extent on clay soils $(x 1.7$ to $\times 7.8)$ than sandy loam soils $(x 1.3$ to $\times 1.4)$; confirming 438 the earlier result that the presence of sands increases soil erodibility.

439 This study provides new and useful understanding of changes in soil erodiblity in response 440 to variations of grazing pressure. The results suggest that spatial variations of soil surface 441 disturbance induced by grazing pressure have a direct impact on soil erodibility to wind. 442 The MWT played a crucial role in this project because its small footprint enabled the 443 positioning of the tunnel between grass clumps; thus testing the soil surface conditions 444 avoiding the complicating effects of vegetation upon wind erosion.

\section{$445 \quad 3.2$ Wind erosion on alluvial claypans}

446 A field study was undertaken on a claypan on the Diamantina River floodplain, Queensland. 447 Claypans as a single unit (covering from 1 - 100s square kilometres in size) are known to 448 be dust source hotspots [32, 33]. However claypans do not comprise uniform surfaces and 449 instead are characterised by a complex mosaic of surface crust types. The aim of this study 
450 was to determine the relative erodibility of each crust type. The erodibility of individual crust 451 types is poorly understood in part because most large portable wind tunnels cover a range 452 of crust types in a single run, thereby homogenising the results. Field experiments were 453 conducted on three crust types; structural, depositional and biological as defined by 454 Valentin and Bresson [34] and Thomas and Dougill [35]. The MWT was used both without 455 and with saltation added.

456 Across the claypan, the sediment flux varied considerably (at $\mathrm{u}=9 \mathrm{~m} \mathrm{~s}^{-1}$ ), with biological 457 crust surfaces yielding a higher sediment flux $(Q)$ than the depositional and structural crusts 458 (Table 3). Sediment flux with saltation added $\left(Q_{\mathrm{SI}}\right)$ is again higher from the biological crusts 459 than the structural and depositional (Table 3). At first sight, these results appear to be 460 inconsistent with other published studies [16,17] which conclude that biological crusts 461 provide greater protection to soils than physically crusted or depositional surfaces. In 462 reality the results probably reflect the capacity of biological crusts to store loose sediment 463 and release it when wind speeds increase. The proportional increase in sediment flux with 464 the addition of saltation sands $\left(Q_{S I}: Q\right)$ is much less for biological crusts ( $x$ 5.6) than 465 depositional and structural crusts (x14 and $x 16$ respectively), indicating that biological 466 crusts are more protective of soils in a saltation impact environment. This result reinforces 467 the earlier interpretation; that the relatively high overall sediment fluxes from biological 468 crusted surfaces reflect their capacity to store loose sediment and release it when wind 469 speeds increase.

470 This result also supports the conclusions from the study by Hupy [36] which showed that 471 the spatial positioning of different surface types can have an important influence upon 472 overall wind erosion rates from a claypan. Hupy [36] found that storage zones of saltation 473 sands, such as the biological crusted regions, provided a source of abrasion material for 474 downwind sites.

475 Table 3 Measured sediment flux $\left(\mathrm{g} / \mathrm{m}^{2} / \mathrm{s}\right)$ at three surface crust types using one MWT wind $\mathrm{speed}, \mathrm{U}=9 \mathrm{~m} \mathrm{~s}^{-1}$

\begin{tabular}{|l|l|l|l|}
\cline { 2 - 4 } \multicolumn{1}{c|}{} & \multicolumn{3}{c|}{ Sediment flux $\left(\mathrm{g} / \mathrm{m}^{2} / \mathrm{s}\right)$} \\
\cline { 2 - 4 } \multicolumn{1}{c|}{} & \multicolumn{1}{c|}{ Structural crust } & Depositional crust & \multicolumn{1}{c|}{ Biological crust } \\
\hline Without saltation added $(\mathrm{Q})$ & 0.109 & 0.316 & 1.117 \\
\hline With saltation added $\left(\mathrm{Q}_{\mathrm{SI}}\right)$ & 1.766 & 4.371 & 6.196 \\
\hline $\begin{array}{l}\text { Saltation entrainment ratio } \\
\left(Q_{\mathrm{SI}}: \mathrm{Q}\right)\end{array}$ & $\times 16$ & $\times 14$ & $\times 5.6$ \\
\hline
\end{tabular}

477 This study provides new and useful understanding of the changes in soil erodiblity across a heterogenous claypan surface. The results suggest that spatial variations of crust types have a direct impact on erodibility and that both the abundance and spatial distribution of 481 the crust types have an effect of the overall sediment flux of a claypan as a whole. The use of the MWT was crucial to the collection of this sediment flux data as its small nature and portability enabled the testing of discrete crust types. Larger field tunnels would have measured the response of either a range of crust types, and/or the patchy vegetation which 484 is commonly associated with the biological crusts on claypans. 


\section{$486 \quad 3.3$ Erodibility of iron ore sediments}

487 A field study was undertaken to assess the relative erodibility of different iron ore sediments 488 within an iron ore port facility in Western Australia. The iron ore storage facility involved 489 receiving, sorting, stacking, transporting via conveyors and ship loading several different 490 ore products. This diverse range of products and material handling activities produced 491 considerable fugitive dust which can have negative impacts upon local communities. The 492 term fugitive dust refers to dust which is mechanically entrained [37] and may be wind493 eroded at mine sites, ore storage areas and mine rehabilitation areas [38, 39]. One 494 measure of the fugitive dust potential of an ore deposit is the surface sediment fluxes 495 resulting from increased wind speeds. Identifying the key sources of dust is an important 496 precursor to applying appropriate dust mitigation strategies. The MWT was used to 497 measure the wind erodibility of different iron ore deposits. MWT measurements were 498 carried out on two iron ore stockpiles and two local ore deposits; on roadsides and beneath 499 the conveyor belts (Table 4).

501 Table 4. Measured sediment flux $\left(\mathrm{g} / \mathrm{m}^{2} / \mathrm{s}\right)$ at two iron ore sites and two deposited sediment sites using one MWT 502 wind speed, $\mathrm{U}=9 \mathrm{~m} \mathrm{~s}^{-1}$

503

\begin{tabular}{|l|l|l|l|l|}
\cline { 2 - 5 } \multicolumn{1}{c|}{} & \multicolumn{3}{c|}{ Sediment flux $\left(\mathrm{g} / \mathrm{m}^{2} / \mathrm{s}\right)$} \\
\cline { 2 - 5 } & \multicolumn{2}{c|}{ Iron Ore surfaces } & \multicolumn{2}{c|}{ Deposited sediments } \\
\cline { 2 - 5 } & Stockpile 1 & Stockpile 2 & $\begin{array}{l}\text { Deposits on } \\
\text { road }\end{array}$ & $\begin{array}{l}\text { Deposits below } \\
\text { conveyor }\end{array}$ \\
\hline Without saltation added (Q) & 1.41 & 0.01 & 78.13 & 4.35 \\
\hline With saltation added (Q & 2.65 & 0.49 & 159.08 & 32.93 \\
\hline $\begin{array}{c}\text { Saltation entrainment ratio } \\
\left(Q_{\mathrm{SI}}: \mathrm{Q}\right)\end{array}$ & $\times 1.9$ & $\times 49.0$ & $\times 2.0$ & $\times 7.5$ \\
\hline
\end{tabular}

504 The highest overall sediment fluxes were recorded on the local ore deposits (on road and 505 under conveyor) and the lowest from the two stockpile ores (Table 4). The very high fluxes 506 on the local ore deposits arose because they were relatively fine dust deposits $(<50 \mu \mathrm{m})$, 507 with low compaction. These deposits were therefore a major potential source of fugitive 508 dusts. The sediment fluxes with saltation material in the airflow $\left(Q_{S I}\right)$ were increased on all 509 sites. While the proportional increase in sediment flux $\left(Q_{S I}: Q\right)$ was greatest on the 510 stockpile 2, the absolute sediment flux was much lower than on the local deposits. The 511 large range in sediment fluxes between sites highlights the complexity of managing fugitive 512 dust emissions at mine sites and iron ore storage areas and the need to adopt a range of 513 different dust mitigation strategies. 
515 The MWT proved to be very well suited to the practical demands of operating at this 516 industrial site; where equipment access and operation was difficult, especially on inclined 517 stockpile surfaces and beneath conveyor belts.

\subsection{Summary of applications of the micro wind tunnel}

520

The MWT has proved to be a valuable tool for assessing small scale soil erodibility issues. The use of the MWT across a range of surfaces provides new and useful understanding of the erodibility of rangelands, claypans and ore stockpiles. There are 3 key attributes of the MWT. First, nimbleness, second flexibility, third operability. The MWT "nimbleness" in getting in and around grass clumps which are a common feature of many rangelands and difficult to measure with larger tunnels provides a true practical advantage. The tunnel is "flexible" in being easily deployed across diverse terrains and in constricted industrial 527 settings. Truck or trailer mounted portable wind tunnels are well suited to large open agricultural paddocks, therefore to apply these tools in a spatially restricted environment often means the test surfaces have to be disturbed and brought to the tunnel, thus altering their natural erodibility properties. Another important feature of the MWT is its "operability". This tunnel can be used, packed up and transported by one person. Larger portable tunnels require multiple people and often heavy lifting aids to assemble and pack the equipment.

\section{Conclusion}

535 The micro wind tunnel (MWT) is a small, portable wind tunnel, operable by one person. 536 The MWT produces airflow velocities ranging from 5 to $18 \mathrm{~m} \mathrm{~s}^{-1}$ with high reproducibility. 537 The velocity profiles show an orderly progression downwind, and the across tunnel contour 538 plots showed a good air speed distribution. Unlike larger wind tunnels, the dimensions of 539 the MWT limit the form of velocity distribution in the working section, but it is these duct like 540 dimensions that enable the shear stress within to be determined from the pressure drop. 541 Through measuring the pressure gradients enables the measurement of drag coefficient 542 and allows the calculation of both sensible $u_{*}$ and surface-roughness measures in the 543 MWT. Saltation feed into the airflow is at the optimal rate of $6.1 \mathrm{~g} \mathrm{~m}^{-1} \mathrm{~s}^{-1}$ and collection 544 efficiency is high.

545 The utility of the MWT is demonstrated from wind erosion studies on rangelands and 546 alluvial claypans, and at an iron ore storage facility. The rangeland study highlights the 547 ease of use of the MWT on surfaces with complex patterns of tufted pasture grasses. At 548 the claypan site the small footprint of the MWT allowed wind erosion simulations to be 549 conducted on different discrete surface crust types. At the iron ore storage facility the MWT 550 proved to be very well suited to the practical demands of operating at an industrial site; 551 where equipment access and operation were difficult; on inclined stockpile surfaces and 552 beneath conveyor belts. The MWT is therefore a valuable wind erosion simulation tool 553 which very well supplements larger portable field wind tunnels. 


\section{Acknowledgements}

557 The authors acknowledge the major contribution to the design and construction of the MWT 558 by their late co-author Mike Raupach who passed away recently. Mike's passing is a great 559 loss to our research community. Thanks to Samantha McMillan for initial testing and 560 development work on the MWT. This work was partially funded by the UK NERC 561 (NE/K011461/1) and Griffith University.

562

\section{Reference}

564 1. Leys JF (1999) Wind Erosion on Agricultural Land. In 'Aeolian Environments, Sediments 565 566 568 and Landforms'. (Eds. Gouldie, A. S., Livingstone, I., and Stokes, S.), pp. 143-166 (John Wiley and Sons).

2. Webb NP, Strong CL (2011) Soil erodibility dynamics and its representation for wind erosion and dust emission models. Aeolian Research 3:165-179

3. Zobeck TM (1991) Abrasion of crusted soils: Influence of abrader flux and soil properties. SSSAJ. 55(4): 1091-1097

4. Goossens D, and Offer ZY (2000) Wind tunnel and field calibration of six Aeolian dust samplers. Atmospheric Environment. 34(7): 1043-1057

5. Van Pelt RS, Zobeck TM, Baddock MC, Cox JJ (2010) Design, construction and calibration of a portable boundary layer wind tunnel for field use. Transactions of the American Society of Agricultural and Biological Engineers 53(5):1-10

6. Etyemezian V, Nikolich G, Ahonen S, Pitchford M, Sweeney M, Gillies J and Kuhns H (2007) The Portable In-Situ Wind Erosion Laboratory (PI-SWERL): A new method to measure windblown dust properties and potential for emissions Atmos Environ 41:37893796

7. Hagen LJ (2004) Evaluation of the Wind Erosion Prediction System (WEPS) erosion submodel on cropland fields. Environmental Modelling and Software 19: 171-176

8. Webb NP, McGowan HA, (2009) Approaches to modelling land erodibility by wind. Progress in Physical Geography 33:587-613

9. Butler HJ, Hogarth WL, and McTainsh GH (1996) A source-based model for describing dust concentrations during wind erosion events: an initial study. Environmental Software 11(1-3):45-52

10. Bagnold RA (1941) The physics of blown sand and desert dunes. William Morrow \& Company, New York 
590

591

592

593

594

595

596

597

598

599

600

601

602

603

604

605

606

607

608

609

610

611

612

613

614

615

616

617

618

619

620

621

622

623

624

625

626

627

11. Chepil WS (1953) Field structure of cultivated soils with special reference to erodibility by wind. Soil Science Society Proceedings 185-190

12. Zhang YM, Wang HL, Wang XQ, Yang WK and Zhang DY (2006) The microstructure of microbiotic crust and its influence on wind erosion for a sandy soil surface in the Gurbantunggut Desert of Northwestern China. Geoderma 132:441-449

13. Maurer T, Hermann L, Gaiser T, Mounkaila M, Stahr K (2006) A mobile wind tunnel for wind erosion field measurements. Journal of Arid Environments 66(2):257-271

14. Nickling WG and Gillies JA (1993) Dust emission and transport in the Male, West Africa. Sedimentology 40:859-868

15. Gillette DA (1978) Tests with a portable wind tunnel for determining wind erosion threshold velocities. Atmospheric Environment 12:2309-2313

16. Belnap J and Gillette DA (1997) Disturbance of biological soil crusts: impacts on potential wind erodibility of sandy desert soils in southeastern Utah. Land Degradation and Development 8:355-362

17. Belnap, J. and Gillette, DA (1998) Vulnerability of desert biological soil crusts to wind erosion: the influences of crust development, soil texture, and disturbance. Journal of Arid Environments 39:133-142

18. Sweeney M, Etyemezian V, Macpherson T, Nickling W, Gillies J, Nikolich G, McDonald E (2008) Comparison of PI-SWERL with dust emission measurements from a straightline field wind tunnel. Journal of Geophysical Research 113:(F01012) doi:10.1029/2007/JF000830

19. Zingg AW (1951) A portable wind tunnel and dust collector development to evaluate the erodibility of field surfaces. Agronomy Journal 43(2):189-191

20. Raupach MR and Leys JF (1990) Aerodynamics of a portable wind erosion tunnel for measuring soil erodibility by wind. Australian Journal of Soil Research 28(2):177-191

21. White FM (1994) Fluid Mechanics. McGraw-Hill, New York

22. Schetz JA and Fuhs AE (1999) Fundamentals of fluid mechanics. John Wiley and Sons, New York

23. Batchelor GK (1967) An Introduction to Fluid Dynamics. Cambridge University Press, Cambridge

24. Raupach MR, Hughes DE and Cleugh HA (2006) Momentum absorption in rough-wall boundary layers with sparse roughness elements in random and clustered distributions. Boundary-Layer Meteorology 120:201-218 
628

629

630 631

632

633

634

635

636

637

638

639

640

641

642

643

644

645

646

647

648

649

650

651

652

653

654

655

656

657

658

659

660

661

662

663

664

665

666

667

668

25. Shao Y and Raupach MR (1992) The overshoot and equilibration of saltation. Journal of Geophysical Research 97(20):559-564

26. Pietersma D, Stetler LD and Saxton KE (1996) Design and aerodynamics of a portable wind tunnel for soil erosion and fugitive dust research. Trans of the ASAE 39:2075-2083

27. Goossens D and Offer ZY (2000) Wind Tunnel and field calibration of six Aeolian dust samplers. Atmospheric Environment 12(12):1043-1057

28. McTainsh GH, Leys JF, and Nickling WG (1999) Wind erodibility of arid lands in the channel country of Western Queensland, Australia. Zeitschrift fur geomorphologie 116:113-130

29. Gillette DA, Adams J, Muhs D and Kihl R (1982) Threshold friction velocities and rupture moduli for crusted desert soils for the imput of soil particles into the air. Journal of Geophysical Research 87:9003-15

30. Aubault HA (2014) Estimating the impacts of pastoral activities upon wind erosion in the arid and semi-arid rangelands of eastern Australia. Ph.D. Thesis, Griffith University

31. Pickup G (1989) New land degradation survey techniques for arid Australia: problems and prospects. Aust. Rangel. J. 11:74-82.

32. McTainsh GH and Leys JF (1993) "Chapter 7 - Wind erosion". In: McTainsh GH and Boughton WC (Eds) Land degradation processes in Australia. Longman-Cheshire, Melbourne pp188-233

33. Reheis MC (2006) A 16-year record of eolian dust in Southern Nevada and California, USA: controls on dust generation and accumulation. Journal of Arid Environments $67: 487-520$

34. Valentin C and Bresson LM (1992) Morphology, genesis and classification of surface crusts in loamy and sandy soils. Geoderma 55:225-245.

35. Thomas AD and Dougill AJ (2006) Distribution and characteristics of cyanobacterial soil crusts in the Molopo Basin, South Africa. Journal of Arid Environments 64:270-283

36. Hupy JP (2004) Influence of vegetation cover and crust type on wind-blown sediment in a semi-arid climate. Journal of Arid Environments 58:167-179

37. Gillies JA, Watson JG, Rogers CF, Dubois D, Chow JC, Langston R, and Sweet J (1999) Long-Term Efficiencies of Dust Suppressants to Reduce PM 10 Emissions from Unpaved Roads. Journal of the Air \& Waste Management Association 49:3-16

38. Cowherd C Jr, Bohn R and Cuscino T (1979) Iron and steel plant open source fugitive emission evaluation; Report No EPA-600/2-79-103. Research Triangle Park, NC, U.S. Environmental Protection Agency, Industrial Environmental Research Laboratory 
669 39. Chan Kon L, Durucan S and Korre A (2007) The development and application of a wind 670 erosion model for the assessment of fugitive dust emissions from mine tailings dumps.

673 International Journal of Mining, Reclamation and Environment 21(3):198-218 